\title{
Congenital tuberculosis: a case series
}

\author{
*Ishita Majumdar ${ }^{1}$, Priyankar Pal ${ }^{1}$, Kheya Ghosh Uttam¹, Rafiqul Hassan ${ }^{1}$
}

Sri Lanka Journal of Child Health, 2017; 46(3): 278-280

DOI: http://dx.doi.org/10.4038/sljch.v46i3.8333

(Keywords: Tuberculosis, Gene Xpert, anti-tubercular drugs, multidrug resistant tuberculosis, acid fast bacilli)

\section{Introduction}

In India, despite the high prevalence of tuberculosis (TB) in women of childbearing age, congenital TB is rarely reported due to clinical variability, diagnostic dilemma and $50 \%$ mortality rate ${ }^{1,2}$. Approximately 30 cases have been reported from India till 2014. Unfortunately, most were diagnosed post-mortem ${ }^{1,3-5}$. We present a 3 cases to create awareness among clinicians that timely diagnosis can save little lives.

\section{Case 1}

A 6 day old preterm boy, weighing 1600g, was admitted with tachypnoea, poor feeding and lethargy for one day for which he had to be ventilated. On examination, there was hepatosplenomegaly with scattered coarse crepitations in bilateral lung fields. Haemoglobin $(\mathrm{Hb})$ level was $7.6 \mathrm{~g} / \mathrm{dl}$, total white cell count $27,400 / \mathrm{cu} \mathrm{mm}$ (N70\%, L26\%, E2\%), microerythrocyte sedimentation rate (micro-ESR) $30 \mathrm{~mm}$ in first hour and C-reactive protein (CRP) 194mg/L. Cerebrospinal fluid (CSF) examination showed 100 cells (N20, L80), protein $105 \mathrm{mg} / \mathrm{dl}$ and glucose $35 \mathrm{mg} / \mathrm{dl}$ (blood sugar $125 \mathrm{mg} / \mathrm{dl}$ ). Chest x-ray showed bilateral diffuse opacities. Even after 5 days of broad spectrum antibiotics, baby was deteriorating clinically and radiologically. Broncho-alveolar lavage (BAL) fluid yielded acid fast bacilli (AFB) and culture was positive for TB. Mantoux test was negative.

\section{Case 2}

A 13 day old term boy of birthweight $2100 \mathrm{~g}$ was admitted with poor feeding, drowsiness, pallor and tachypnoea for 2 days. He had prolonged capillary refill time (7 seconds), hepatosplenomegaly and bilateral diffuse crepitations over the lungs. $\mathrm{Hb}$ level

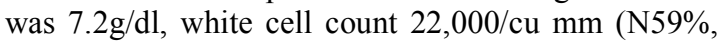
L45\%, E4\%), micro-ESR 24mm in first hour and CRP $140 \mathrm{mg} / \mathrm{L}$. Chest $\mathrm{x}$-ray showed diffuse miliary shadowing bilaterally. The CSF study was normal.

\footnotetext{
${ }^{1}$ Institute of Child Health, Kolkata, India

*Correspondence: ishita.m26@gmail.com

(Received on 26 March 2016: Accepted after revision on 20 May 2016)

The authors declare that there are no conflicts of interest

Personal funding was used in formulating the article.

Open Access Article published under the Creative

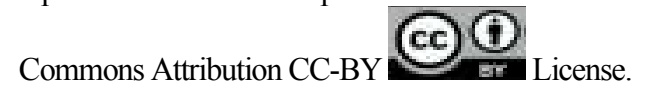

Broad spectrum antibiotics failed to generate any response. Mantoux test was negative. Gastric aspirate yielded AFB and culture was positive for TB. Liver biopsy revealed caseating granulomatous lesions.

\section{Case 3}

A 25 day old boy was admitted with not gaining weight. Baby was febrile, tachypnoeic with hepatosplenomegaly. Hb level was $8.0 \mathrm{~g} / \mathrm{dl}$, white cell count $25,000 / \mathrm{cu} \mathrm{mm} \mathrm{(N60 \% ,} \mathrm{L30 \% ,} \mathrm{E4 \% ),} \mathrm{micro-}$ ESR $26 \mathrm{~mm}$ in first hour and CRP $100 \mathrm{mg} / \mathrm{L}$. The CSF study was normal. Chest x-ray showed diffuse miliary shadowing bilaterally. Chest computer tomography (CT) scan revealed bilateral caseating granulomatous lesions as shown in Figure 1.

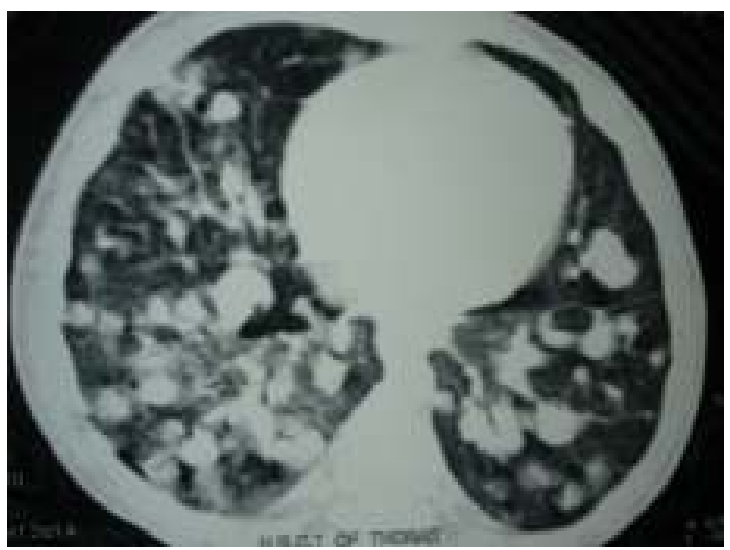

Figure 1: Computer tomography scan of chest showing bilateral caseating granulomatous lesions

Mantoux test was negative. Gastric aspirate for AFB was negative. Baby developed multiple cervical and axillary lymph nodes, which progressively increased in size with discharging sinus in one node. AFB were isolated from ear discharge and culture was positive for TB.

Mother was diagnosed to have pulmonary TB in cases 1 and 2 and TB of uterus in case 3. The first and second cases were treated with 4 anti-tubercular drugs (ATDs), isoniazid $(10 \mathrm{mg} / \mathrm{kg} / \mathrm{day})$ and rifampicin $(10 \mathrm{mg} / \mathrm{kg} /$ day) for 10 months, pyrazinamide (20mg/kg/day) and amikacin $(15 \mathrm{mg} / \mathrm{kg} /$ day) for 2 months and intravenous dexamethasone followed by oral prednisolone for 1 month (stopped in a tapering fashion). In the third case, treatment was initiated with 4 ATDs and because of poor response with 
progressively increasing lesions even after 2 months, 8 ATDs were given as in multidrug resistant (MDR) TB with a successful outcome. All the close contacts (father, grandparents) of case 1 and 2 were screened for TB and found to be negative.

\section{Discussion}

Infection with tubercle bacilli either during intrauterine life or before complete passage through the birth canal is termed congenital TB. It occurs in 3 ways: transplacental acquisition in liver (haematogenously), aspiration in lungs or by ingestion in gut $^{6}$. Clinically $\mathrm{TB}$ in newborn infants simulates bacterial sepsis or other congenital infections like syphilis or CMV. Symptoms may be present at birth but are usually seen in the second or third week. Hepatomegaly is found in $76 \%$, respiratory distress in $72 \%$, fever in $48 \%$ and lymphadenopathy in $38 \%{ }^{7}$. Prognostic factors include age of onset, presence of intracranial lesions, ATDs, specific image performances and leukocyte count ${ }^{8}$.

In 1935, Beitzke presented criteria for diagnosis of congenital TB differentiating it from perinatal TB but as these were very rigid, modified criteria proposed in 1992 by Cantwell et al are being used ${ }^{9}$. According to Cantwell criteria, the infant must have a proven TB lesion and at least one of the following: lesions in first week of life, primary hepatic complex or caseating hepatic granuloma, tuberculous infection of placenta or maternal genital tract and exclusion of postnatal transmission by thorough contact investigation. Our first and second cases had proven tuberculous lesions in the lungs with bacilli isolated from BAL fluid and gastric aspirate respectively. In the third case, tubercle bacilli were isolated from ear discharge. Contact was the mother in all 3 cases. Thus all three cases meet the Cantwell criteria of congenital TB.

In neonatal sepsis, babies are usually leucopenic. However, all 3 cases in the present series had significant leucocytosis with very high CRP. Neonatal TB may be multibacillary which can be the possible explanation for this high gastric aspirate and BAL positivity along with the use of very sensitive gene Xpert test. Only one baby had associated asymptomatic meningitis, though CSF study was done in all patients.

Usage of steroids remains controversial in congenital tuberculosis. All the babies in our series received steroids with rapid diminution in respiratory support requirement. Since neonatal TB is akin to miliary TB, possibly it should be considered in select cases depending on the physician's discretion ${ }^{10}$. In all 3 cases presenting as sepsis / pneumonia, non-response to broad spectrum antibiotics, strong clinical suspicion and early initiation of ATDs helped us save lives. None of the mothers had a known history of TB and diagnosis was made retrospectively in all the cases and treatment started.

The importance of early diagnosis and treatment of this condition is crucial because consequences of delayed diagnosis and therapy are serious. Mortality has reduced after ATD treatment ${ }^{7}$. Improved screening of women at risk and sensitization of the medical community are necessary.

\section{References}

1. Balasubramaniam S, Shivram R, Padmasani LN, Nagarju. Congenital tuberculosis. Indian Journal of Pediatrics 1999; 66(1):148-50. https://doi.org/10.1007/BF02752376

2. Mittal H, Das S, Faridi MMA. Management of newborn infant born to mother suffering from tuberculosis: Current recommendations and gaps in knowledge. Indian Journal of Medical Research 2014; 140(1):32-9. PMid: 25222775 PMCid: PMC4181157

3. Singh T, Natt NK, Sharma M, Singh $H$. Congenital tuberculosis complicated by interstitial pulmonary emphysema. Journal of Clinical Neonatology 2014; 3(1):41-3. https://doi.org/10.4103/2249-4847.128731 PMid: 24741540 PMCid: PMC3982339

4. Neyaz Z, Gadodia A, Gamanagatti S, Sarthi M. Imaging findings of congenital tuberculosis in three infants. Singapore Medical Journal 2008; 49(2):e42-6.

PMid: 18301825

5. Das A, Arora J, Rana T, Porwal C, Kaushik A, Gaur G et al. Congenital tuberculosis: the value of laboratory investigations in diagnosis. Annals of Tropical Paediatrics 2008; 28(2):137-41. https://doi.org/10.1179/146532808X302161 PMid: 18510824

6. Chan A, Shih SL. Congenital tuberculosis in two infants. American Journal of Roentgenology 2004; 182(1):253-6. https://doi.org/10.2214/ajr.182.1.1820253 PMid: 14684547

7. Hagemen J, Shulman S, Schreiber M, Luck S, Yogev R. Congenital tuberculosis: critical reappraisal of clinical findings and diagnostic procedures. Pediatrics 1980; 66(6):980-4.

8. Peng W, Yang J, Liu E. Analysis of 170 cases of congenital TB reported in the 
literature between 1946 and 2009; Pediatric

Pulmonology 2011; 46(12):1215-24.

https://doi.org/10.1002/ppul.21490

PMid: 21626715

9. Cantwell MF, Shehab ZM, Costello AM, Sands L, Green WF, Ewing EP Jr et al. Brief report: congenital tuberculosis; New England Journal of Medicine 1994; 330(15): 1051-4.

https://doi.org/10.1056/NEJM199404143301 505

PMid: 8127333

10. Pal P, Ghosh A. Congenital tuberculosis: Late manifestation of the maternal infection. Indian Journal of Pediatrics 2008; 75(5): 516-8 https://doi.org/10.1007/s12098-008-0082-X PMid: 18537017 